reference to the report it will be found thint diarrhcea was an early symptom on the 6 th, although the motions were not examined until the $8 \mathrm{th}$, on the evening of which day the first attack of vomiting occurred. Distinguished then from hrmatemesis, in which danger is comparatively speaking rare, the above case assumes the character of one quite as frequently fatal, the Melana splenetica of Saurages; the Soecsims niger of Hoffman; the Melcena cruenta of Good, and becomes sufficiently interesting I think to be recorded among the practical papers of our Journal. With regard to the treatment of the case, it will be perceived that I was nore anxious to meet the symptoms ds, they occurred, and assist nature in perfecting ber own cure, than to prescribe for the assumed plrenomena of a disease, the pathology of which, notwithstanding the researclies of Portal and others, still remains in considerable obscurity. I think the turpentine was of service, although only given in a quarter of the dose advised by Dr. Elliotson.

Stowmarket, October 24, 1845.

\section{DR. SHEARMAN'S CASE OF MALFORMATION OF THE HEART.}

TO THE EDITOR OF THE PROVINCIAL MEDICAL AND Str, SURGICAL JOURNAL.

Will you kindly allow me to ask of Dr. Shearman, through the mediun of your pages, some questions relative to his case of inalformation of the heart, reported in the Journal of July 30, 1845 ?

It appears that the pulmonary artery "was quite rudimentary ;" that into the left auricle only one very minute venous orifice could be found; and that there existed a largish venous trunk, communicating with the right auricle, and provided with a valve, which took "a circular course round the base of the heart." It appears further, that the little patient, in the space of a twelvemonth, had had several attacks of hæmoptysis, to the anount of froin one to two pints of "florid" blood each time; and that both lungs were tubercular. Dr. Shęarman asks whether this latter-state will account for the bremoptysis ? or if not, what was its cause?

I think it is important first to determine how the capilinaries of the pulmonary artery in the lungs were supplied with blood, since the trunk of the pulmopary artery was "quite rudimentary." Was the circulation carried on in a retrograde manner from the aorta througli the ductus arteriosus into the right and left pulmonary arteries? or was there any other mode of coipmunication between the right ventricle and the lungs ?

A g nin, how did the aerated blood find its way into the feft ventricle? Through the largish venous vessel wincting round the base of the heart? If not, whence did this winding vessel receive its blood?

With respect to the blowing sounds, Dr. Shearman's explanation of that heard at the ensiform cartilage, being due to tricuspid regurgitation, is quite satisfactory; the locality of the sound, and the time of its occuring, taken in connexion with the great jugular pulsation, sufficiently point out the lesion. That the systolic murmur over the sternum, near the third rib, was due to the meeting of the two stresins of blood, at the hole in the septum, appears more doubtful. I should bave thought that this was more likely to have caused the feeble bellows-sound at the apex; but then the former is to be accounted for. Now, I would ask Dr. Shearman, if, from the appearance of the aperture of the winding ressel and its valve in the auricle, there may not have been considerable regurgitatiou into this vessel at each ventricular contraction, and whether this may not have given the sonnd deemed to indicate aortic disease?

This question is, of course, only to be determined by the correspondence, or otherwise, of the situation of this orifice with the situation of the murmur, and the admission or not of regurgitation through it.

If this ressel was the afferent of the aerated blood from the lungs, and these organs received their supply through the ductus acteriosus or any other brancli of the aorta, then the hremoptysis is fully accounted for; for the lungs are injected by both ventricles at once through the aorta; while, in consequence of the free tricuspid regurgitation, and the supposed regurgitation through the peculiar valve, both ventricles in like inanner combine to inject the lungs through the winding "venous vessel." The lungs being thus injected through both the arterial and venous trunks; by the united force in each case of both ventricles, no wonder hæmoptysis was the result.

I trust Dr. Shearman will pardon the observations I have made, and the questions I have asked. I should not have taken this liberty but for the invitation with which he has been pleased to close his clear and simple statement of this very interesting case. If he would give the subject any further consideration, and communicate the result in the Journal, I should feel greatly obliged, and I hope you, Sir, would not think your space unprofitably occupied.

I am, Sir,

Your obedient servant,

Yeovil, Oct. 22, 1845.

F. NESBITT.

\section{UNIVERSITY COLLEGE HOSPITAL.}

\section{CASE OF SUB-ACUTE GASTRITIS.}

Reported by Mr. John Elliotr Wood, late Clinical Clerk in the Hospital.

Elizabeth Jones, aged 27, single, was admitted under Dr. A. 'T. Thoinsun, April 30, 1845. She is of middle height, sanguine tempersment, and fair complexion. She has been a housemaid for the last seven years, living in an open and airy siturtion in Landon, and always having a sufficiency of food and clothing. Her health has always been good till the present attack; she has never suffered from any acute disease, and not been subject to dyspepsin. On examination at the time of her admission into the hospital, it was ascertained that the present attack commenced two months ago, with giddiness in the head, sickness, loss of appetite, and pain in the region of the lumbar vertebra; these symptoms increased, and she soon felt a disinclination to take anything but acids. About three weeks ago she began to throw up whatever she took, and since that time she has been unable to keep anything on her stomach. At present, (A pril 30th,) she vomits continually, complains of pain on pressure at the epigastrium, with great prostration "of strength; 
the colour of the skin is natural, it is dry and rather hot; slie has lost flesh lately, and is now very thin. She is unable to sleep, on account of the almost incessant vomiting; she has no desire for food; there is a scanty evacuation from the bowels daily; and there is no general abdominal tenderness; the tongue is clean; pulse small, 112; the urine deposits phosphates. Before her admission she had taken medicine for a fortnight, and a blister had been applied to the epigastrium, but without much benefit.

She: was now ordered :-Acid. Hydrocyan ; Dil.; M. v.; Sodæ Sesqui-carb, gx. x.; Aquæ, oz., iss., ter die. Two leeches to the epigastrium. A common purgative enema to be administered. To take arrowroot and beef tea.

May 3rd. The symptoms continued without any abatement in their intensity, and without change in character. The mixture was discontinued, and the following ordered:-Liq. Potass.; M.x. Acid. Hydrocyan. Dil. M. v., Mist. Amygd. Amar., oz. iss., ter die. A rubefacient plaister to the epigastrium; the purgative enema to be repeated.

5th. There is no improvement. All medicines to be discontinued.

6 th. The romiting still continues, with the pain at the epigastrium; pulse sharp, small, 112 ; countenance anxious; angles of the mouth rather livid. The plaister to be removed; cupping to twelve ounces in the epigastric region; no food to be taken by the mouth; enemata of strong beef tea to be administered.

8 th. She has less pain on pressure, and the stomach feels more comfortable; the romiting has abated; she is very weak and exhausted. A little ice to be taken; the nutritive enemeta continued; and a blister applied to the epigastrium.

10th. There has been no vomiting since the last report ; but there is still considerable pain on pressure ; pulse improved; tongue moist and clean. Twelve leeches to the epigastrium; to continue the enemata.

13th. A little beef tea was given to-day, which produced no return of vomiting, nor feeling of uneasiness at the stomach. She is improved in all respects. A blister to the epigastrium ; the enemata to be onitted. To have beef tea with arrowroot.

15th. The stomach now retains food of a light kind, and she has no pain after taking it; the bowels continue regular; pulse soft.

17th. She is still improved; tongue clean; feels much stronger; there has been no vomiting.

20th. She can now take solid food with impunity. $A$ rubefacient plaister was applied to the pit of the stomach; she continued to improve, and was discharged cured on the 27 th.

Remark8.-This case presents many points of considerable interest and importance, more especially as the success of the treatment, both medicinal and dietetic, was so very unequivocal. There were certain symptoms in the commencement of the attack which might bave led to a suspicion of hysteria, but the constant vomiting, the pain on pressure at the epigastrium, the great emaciation, and the state of the pulse left no doubt as to the existence of inflammation. It will be observed that in the commencement of the treatment, and before the severity of the disease was discovered, medicines of a sedative character were given by the mouth; a small quantity of blood was taken from the seat of the disorder, and a mild degree of counter-irritation established on the surface. Subsequently, however, more blood was taken locally, and nothing given hy the mouth, either in the shape of food or medicine, for seven days, the patient being supported by enemata. An important element in the treatment was the abstraction of blood from time to time from the neighbourhood of the affected organ; ; and the constant counter-irritation kept up in the same loeality from the date of the patient's admission till her dismissal from the hospital.

The case furnishes us with a remarkable example of the fact that; on certain occasions, more good may be effected by abstaining from medicines than by administering them.

\section{PROVINCIAL \\ fitedical \& Surgíal Fournal.}

WEDNESDAY, NOVEMBER .5, 1845.

The Central Committee of the Benevolent Fund of the Provincial Association have put forth a statement, which will be found in another column of this week's Journal. We would briefly draw attention to it, because it points out in a very satisfactory manner the advantages which have been derived, limited though its means have been, from this very excellent department of the Association.

The objects of the Benerolent Fund and of Mr. Daniell's Medical Anuuity Fund appear to us abondantly distinct, and it would not be difficult to show that the establishment of the latter, supposing it to be carried into extensive and beneficial operation, can never supersede the necessity of some such provision as the former. We have not room to enter into this question on the present occasion, and moreover, deem it advisable to withhold any extended observations on the subject until after the proposed meeting of the subscribers, a notice of which is given in our last page, shall have taken place. We cannot, however, but observe, that the progress of the Benevolent Fund has, we fear, been impeded by the proposals, from time to time brought forward, for making the contributions to its support compulsory on all the members of the Association, either by an addition to the annual subscription, or by the divesting of a portion of the funds contributed for other purposes to this object. The principle on which the Benevolent Fund rests its claims to support should be free and unconstrained, and we have reason to know that some have been withheld from becoming subscribers, in consequence of the uncertainty in which the question has of late been kept. 